\title{
Testing the Promise of Access to Justice through Online Courts
}

\author{
Bridgette Toy-Cronin, Bridget Irvine, David M. Nichols, Sally Jo Cunningham \& \\ Tatiana Tkacukova*
}

\begin{abstract}
Modernization is increasingly knocking on the courthouse door. Many common law countries are investigating ways to introduce technology to improve civil courts, including the introduction of online courts. These state-led initiatives are primarily focused on lowering state costs in providing justice, as well as increasing access to dispute resolution. One possible solution some legal jurisdictions are exploring is 'online courts'. Online courts hold the promise of making justice more accessible and affordable: a dispute can be filed at any time, from anywhere, by anyone. This model of delivering justice is envisioned as a system that either is lawyer-less or has a minimal role for lawyers. One of the assumptions underpinning an online court is, therefore, that laypeople can effectively explain a dispute to the court, without legal assistance. To date, there is no empirical research investigating that assumption. In this article, we will outline the proposed online court model, consider the need for robust empirical research, and describe a three-part investigation to explore how clearly and accurately people can explain a dispute.
\end{abstract}

Keywords: online courts, empirical research, civil justice, access to justice.

\section{The Online Court}

Online courts aim to move the civil adjudicatory process out of the physical courtroom and into an online space, allowing for filing and adjudication without attending a court in person. This model also integrates online dispute resolution (ODR) processes to facilitate settlement between the parties and avoid the need for an adjudicated outcome. Proponents of the model insist that an online court must not simply transplant the paper-based system into the online world; instead, the objective is to:

* $\quad$ Bridgette Toy-Cronin is the Director of the University of Otago Legal Issues Centre and a Senior Lecturer in the Faculty of Law, University of Otago. Bridget Irvine is a Postdoctoral Fellow at the University of Otago Legal Issues Centre. David M. Nichols is an Associate Professor in Computer Science at the University of Waikato. Sally Jo Cunningham is an Associate Professor in Computer Science at the University of Waikato. Tatiana Tkacukova is a Senior Lecturer in the School of English, Birmingham City University. Authors appear in order of the contribution made to the paper. 
[...]put the court user in focus and flip the traditional court model, creating a justice model that focusses on early and collaborative dispute resolution, empowering the parties to reach resolutions to their disputes without the involvement of a judicial officer or the need to attend a physical court. ${ }^{1}$

The end-to-end model provides three stages that litigants proceed through to resolve their dispute: online exploration/evaluation, online negotiation/facilitation, and online adjudication.

The most ambitious version of the online court model is being attempted in England and Wales. ${ }^{2}$ Less ambitious or more incremental models are appearing around the globe. British Colombia's Civil Resolution Tribunal (CRT), for example, is the world's first fully integrated online tribunal. It has been resolving strata $^{3}$ claims for 6 years and more recently has begun resolving general civil small claims. ${ }^{4}$ Many other jurisdictions are making ventures into online courts, including Singapore, Denmark, some of the states of the United States, and Australia. $^{5}$

\subsection{Access to Courts $\neq$ Access to Justice}

The key promises of the online court are cost saving for state providers and access to justice for litigants. While the rhetoric around the online courts emphasizes access to justice, there is limited attention to this aspect in the detail:

A criticism [...] is that the modernisation programme [in England and Wales] is proceeding on the basis of a concern for expenditure but is not paying the same attention to access to justice [...] The whole modernisation programme needs to be submitted to an access to justice audit. ${ }^{6}$

What is the basis of the claim that an online court will increase access to justice? It rests primarily on the idea that for litigants, there will be increased ease of access, speed, and cost saving. Litigants will be able to interact directly with an online portal at any time, from anywhere. ${ }^{7}$ While litigants may still seek legal assistance, the online court systems generally envisage a reduced or minimal role

1 K. Palmgren, Explore the Use of Online Dispute Resolution to Resolve Civil Disputes: How to Best Integrate an Online Court into the Victorian Public Justice System, Winston Churchill Memorial Trust, Canberra, 2018, p. 16.

2 Lord J. Briggs, Civil Courts Structure Review: Final Report, 2016.

3 Strata is a form of property ownership through a legal entity known as the strata corporation and is used for condominiums where there are multiple owners. In other countries it is known by other terms such as 'body corporate'.

4 S. Salter, 'Online Dispute Resolution and Justice System Integration: British Columbia's Civil Resolution Tribunal', Windsor Yearbook of Access to Justice, Vol. 34, No. 2, 2017, pp. 112-129.

5 R. Smith, Annual Report on Developments 2017-18: Digital Delivery of Legal Services to People on Low Incomes, 2018; Joint Technology Committee, Resource Bulletin: Case Studies in ODR for Courts: A View from the Front Lines, Version 1.0, adopted 29 November 2017; Palmgren, 2018.

6 R. Smith, Digitalisation and the Courts of England and Wales, 2018, available at: https://law-techa2j.org/odr/digitalisation-and-the-courts-of-england-and-wales/ (accessed 19 December 2018).

7 Lord J. Briggs, Civil Courts Structure Review: Interim Report, December 2015. 
for lawyers. This is a key component of the access to justice claim - that people will not have to pay for legal representation:

The aim of the online court is to increase access to the civil justice system by providing ... a user-friendly platform that in plain English provides legal information and tools so as to allow court users to understand their legal problem and empower them to present their best case and resolve their disputes without legal representation. ${ }^{8}$

The starting assumption of the online court model is that laypeople have the ability to clearly and accurately explain a justiciable dispute, as long as the interface is sufficiently 'user-friendly and accessible'. ${ }^{9}$ In the current court system - taking place in physical courtrooms - there is very little confidence that laypeople can perform this task. Extra-judicial speeches, as well as judgments and articles, are replete with references to laypeople's failings in this area. ${ }^{10}$ As Lord Justice Briggs, a chief proponent of the online courts in England and Wales, has said, currently civil proceedings rely on "the litigant turning a blank sheet of paper into particulars of claim, an adversarial process that LIPs (litigants in person) tend not to perform with distinction". ${ }^{11}$ There are aspects of preparing court documents that LIPs struggle with, such as determining relevance, separating evidence from submission, and presenting documents in a logical and coherent way. ${ }^{12}$ We know that many laypeople present claims in a narrative form and do not engage easily with the type of analysis preferred by law. ${ }^{13}$

Substantial faith is being placed in the online platform to be able to "guide the litigant through an analysis of his or her grievance in such a way as to produce a document capable of being understood both by opponents and by the court" ${ }^{14}$ While this appears on the face to be impressive, there is a dearth of detail that explains how this will be achieved. As Condlin says:

Sadly, detailed illustrations [of how online dispute resolution will work in practice] are hard to come by. The scholarly literature is devoid of transcripts

$8 \quad$ Palmgren, 2018, p. 18.

9 Ibid.

10 Chief High Court Judge Justice H. Winkelmann, Access to Justice - Who Needs Lawyers?, Ethel Benjamin Address, Dunedin, 2014; A. Zuckerman, 'No Justice without Lawyers - The Myth of an Inquisitorial Solution', Civil Justice Quarterly, Vol. 33, 2014, pp. 355-374; Craig v. Stringer 362 (New Zealand High Court, 2016); Corbett v. Western, 3 NZLR 41 (New Zealand High Court, 2011); Conroy Removals Limited v. Sameer 698 (New Zealand High Court, 2018).

11 Briggs, 2015, p. 76.

12 B. Toy-Cronin, Keeping Up Appearances: Accessing New Zealand's Civil Courts as a Litigant in Person (PhD thesis, University of Otago), 2015.

13 J. Conley \& William O’Barr, Rules versus Relationships: The Ethnography of Legal Discourse, Chicago and London, University of Chicago Press, 1990.

14 Briggs, 2015, p. 76. 
and richly detailed ethnographies and full of self-serving generalities and selfsealing conclusions. ${ }^{15}$

Proponents of the online courts envisage a large role for mediators or facilitators in the process. This is the idea that once filed, a claim will go through party-party negotiation and then, if unsuccessful, facilitation. The facilitator will gather information and refine the dispute. ${ }^{16}$ This process occurs before adjudication (and only if the facilitation is unsuccessful), so it arguably reduces the need for accuracy in the initial claim as the facilitator can make up for any deficits. There are a number of points to note about the ability of facilitation to compensate for any deficiencies in the accuracy of the initial claim and defence. First, the cost savings for the state that are central to the model will not occur if the system relies on a large role by the facilitator. This will be an expensive human effort. Second, not all models have compulsory facilitation or mediation built in. In Money Claim Online, an online court currently operating in England and Wales, there is no compulsory facilitation or mediation. ${ }^{17}$ Third, initial errors in the claim or defence can draw in parties to the claim who have no liability. For example, in a debt claim, a litigant may claim against multiple parties when only one of those parties owe any legal obligation. The innocent defendants will have to go through the process of defending the claim and may even settle during negotiation, despite having no legal liability. Fourth, there are issues around facilitator neutrality if the facilitator is required to take a large role in refining the factual basis of the dispute, particularly if one party needs a lot of assistance. It is, therefore, vital that people are able to explain their dispute accurately and clearly, so the relevant material is presented in a way that the opposing party and the third party (be it mediator, facilitator, or adjudicator) can understand.

It is also important to keep in mind the role of a court. The civil court's purpose goes beyond dispute resolution between the parties. It also has functions in the creation and public statement of rules of common law. A court functions to specify "standards of socially desired behaviour in order to promote compliance with them". ${ }^{18}$ This has import for upholding both the capitalist economy and democracy, as civil justice "provides the legal structure for the economy to operate effectively and for the power of government to be scrutinized and limited" ${ }^{19}$ As Genn says:

R. Condlin, Online Dispute Resolution: Stinky, Repugnant, or Drab?, University of Maryland Legal Studies Research Paper, 2016, p. 13. See also demonstrations of the British Columbia model (https://youtu.be/YMXNnZPc3q0?t=29m) and the England and Wales model (https://youtu.be/ VEItwvisanQ? $\mathrm{t}=45 \mathrm{~m}$ ), which both demonstrate continued use of free text boxes after some basic questioning by way of algorithm about the nature of the disputes and parties to the dispute.

16 This is the model used in the CRT, among others.

17 HM Courts and Tribunal Services, Money Claim Online (MCOL) - User Guide for Claimants, available at: https://assets.publishing.service.gov.uk/government/uploads/system/uploads/ attachment_data/file/762843/mcol-userguide-eng.pdf (accessed 15 January 2019).

18 W. Landes \& R. Posner, 'Adjudication as a Private Good', Legal Studies, Vol. 8, 1979, p. 236.

19 H. Genn, Judging Civil Justice (The Hamlyn Lectures 2008), Cambridge and New York, Cambridge University Press, 2010, p. 16. 
In determining the merits in individual disputes, the judiciary are publicly stating the law, reinforcing norms of social and economic behaviour, identifying the limits of executive power and publicising the values of the society. ${ }^{20}$

Given this wider public purpose, it is not enough for the parties to be subjectively satisfied with their experience of an online court. More is needed. To function as a court, there must also be a level of accuracy in the determinations made so that decisions uphold the rule of law: "a balance must be struck between the needs of justice and needs of the public." 21

\section{The Value of Empirical Research}

To date, the research on online courts has focused on evaluations using descriptive statistics (e.g. how many claims are filed, pace of resolution) and user-experience feedback. User-testing with key stakeholders (e.g. community legal advocates, public) occurs during the development of the platform and direct feedback once the system is implemented. ${ }^{22}$ For example, the CRT reports biannually on user experiences:

The participant satisfaction survey results remain strong, with $77 \%$ indicating they are likely to recommend the CRT to others and $82 \%$ agreeing or strongly agreeing that they were treated fairly throughout the process. ${ }^{23}$

The analysis of user feedback provides important insights about the usability of the portal's interface, and iterative design means the system is responsive to the feedback received. This type of design process puts users at the centre and makes their satisfaction a key measurement.

This type of testing, however, tells us very little about whether users are accurately, clearly, and completely explaining their disputes in the portal. Nor does it tell us what is lost or gained by removing lawyers from the forum. Our research project aims to explore these issues. The project has three research questions:

1 How effective are laypeople at accurately and clearly translating a justiciable dispute into a legally coherent claim?

2 How effective are lawyers at performing this task, compared to laypeople?

3 What innovations might assist laypeople to explain their dispute to the court?

20 Ibid.

21 S. Salter \& D. Thompson, 'Public-Centered Civil Justice Redeisgn: A Case Study of the British Columbia Civil Resolution Tribunal', McGill Journal of Dispute Resolution, Vol. 3, Nos. 113-136, 2016-2017, p. 124.

22 Salter, 2017; Salter \& Thompson, 2016-2017.

23 Civil Resolution Tribunal, Participant Satisfaction Survey - April to September 2018, 2018, available at: https://civilresolutionbc.ca/participant-satisfaction-survey-april-september-2018/ (accessed 19 December 2018). 
We have developed a mixed methods investigation to answer these questions: (1) analysis of District Court files, (2) laboratory testing of how laypeople versus lawyers explain a dispute, and (3) laboratory testing of technology-assisted online evidence acquisition. We will briefly describe the methods we are employing to answer the research questions.

\subsection{Phase I: Analysis of District Court Files}

The first strand of the research is an analysis of claims and defences for general civil proceedings filed in New Zealand under the District Court Rules 2009 (the 2009 Rules). ${ }^{24}$ Proceedings under the 2009 Rules were filed by way of a pre-printed form that the litigants completed. The 2009 Rules "had as their objective an enhancement of access to justice by creating a relatively informal way of commencing a claim or defence". ${ }^{25}$ Like online courts, the intent of the 2009 Rules was to introduce a simplified form through which litigants could explain their dispute to the court without the assistance of the lawyer. This innovation was widely regarded - at least within the legal profession - as a failure, and formal pleadings were reinstated through the District Court Rules 2014 Act. This change was the result of consultation on the 2009 Rules, which concluded that the forms had not achieved their objective and "the need for clarity in the nature of the issues and relief sought was widely recognised by the profession". ${ }^{26}$ This part of the project aims to learn lessons from a previous New Zealand attempt to make the court accessible without the assistance of a lawyer.

\subsubsection{Outline of Phase I Methods}

No systematic review was undertaken to establish why these forms failed. ${ }^{27}$ Previous research on LIP communication suggests the failings could have ranged from adopting a faux-legal register (e.g. Latin terms, strained constructions) to including emotion-laden content and irrelevant material, making it difficult for the judge to understand the claim. ${ }^{28}$ Other factors, previously unidentified, might also account for this failed initiative.

In New Zealand, the District Court is the largest court and has civil jurisdiction for disputes up to a value of $\$ 350,000$.

25 A. Beck et al., District Court Procedures: Review and Reform, Wellington, New Zealand Law Society Continuing Legal Education, 2014.

26 Beck et al., 2014.

27 Telephone conversation with Judge Brooke Gibson (Toy-Cronin, July 2017).

28 R. Abel, 'The Professional is Political', International Journal of the Legal Profession, Vol. 11, 2004, p. 136 (discussing how law students adopt Latinisms as a mark of professional distinction); Rosemary Hunter et al., The Changing Face of Litigation: Unrepresented Litigants in the Family Court of Australia, Sydney, Law and Justice Foundation of New South Wales, 2002, p. 135 (discussing LIPs' citation of case authority because they sense it is "the 'right' way to run a case, thus giving their matter a sense of legitimacy in the eyes of the Court"); T. Tkacukova, 'Communication in Family Court: Financial Remedy Proceedings from the Perspective of Litigants in Person', Journal of Social Welfare and Family Law, Vol. 38, No. 4, 2016, pp. 430-449; T. Tkacukova, 'A CorpusAssisted Study of the Discourse Marker 'Well' as an Indicator of Institutional Roles: Professional and Lay Use in Court Cases with Litigants in Person', Corpora, Vol. 10, No. 2, 2015, pp. 145-170. 
We have collected a random sample of forms that were filed - by both LIPs and lawyers - in New Zealand under the 2009 Rules. The typed forms have been scanned and converted into a machine-readable format for analysis and the handwritten forms typed for analysis.

\subsubsection{Outline of Phase I Analyses}

We are analysing these forms using both qualitative and quantitative methods. We are compiling the forms as linguistic corpora, which allows us to explore patterns in lay communication strategies and compare them against lawyer communication strategies. The quantitative analysis of lexical, grammatical, and syntactic features will lead to a qualitative investigation of narrative strategies used by LIPs, the degree of legal coherence of such narratives, as well as the distinctions in legal-lay discourse types.

\subsection{Phase II: Laboratory Testing of How Laypeople Versus Lawyers Explain a Dispute}

The assumption that litigants will be able to effectively explain their dispute to an online court presents a testable hypothesis. In a laboratory setting, we can explore how laypeople explain disputes and then compare their responses to the perceived 'gold standard' way of litigating a dispute: through a lawyer. By conducting these investigations under laboratory conditions, we can systematically control the information the participants receive about the dispute and then objectively measure how that information is reported back.

\subsubsection{Outline of Phase II Methods}

We have constructed a fictional loan dispute between two family members. ${ }^{29}$ To begin the experiment, the research participant (either a layperson or a lawyer) is given a bundle of materials about the dispute, including a narrative account and some documents (e.g. text messages, e-mails, banking documents). A research assistant plays the part of the litigant who wants to bring a claim against the family member who has failed to repay the loan. The participant is given the opportunity to interview the research assistant, asking any question he or she wants so that the participant can elicit sufficient information about the dispute to write the claim. The participant is then asked to lodge a claim in a faux-online court portal, pleading the case for the litigant. The portal is modelled on the CRT portal.

Lay research participants were recruited from the local community (selected to be a representative sample of the community) and met the research assistant in person. Lawyer participants are more difficult to recruit as we have invited only lawyers with at least 3 years litigation experience and we need a 3-hour block of their time. We are, therefore, inviting lawyer participants from across New Zealand and conducting the interview with the research assistant via videoconference. This gives us two groups to compare - experienced litigation lawyers and laypeople - both who file a claim on behalf of a litigant.

29 The fictional dispute was designed by the research team and two civil litigators. This ensured that the dispute was suitable for the laboratory setting while maintaining ecological validity. 
The use of a layperson to explain a litigant's dispute is based on the findings that litigants commonly use a lay assistant (e.g. a family friend) to help them interact with the justice system. ${ }^{30}$ This design avoids the difficult issue of how we would otherwise be able to provide the detail to the layperson to explain the case as if it were their own dispute.

\subsubsection{Outline of the Phase II Analyses}

The data from this phase of the experiment is both the information the participants input into the portal and the interviews between the research participant and the research assistant, which are recorded and transcribed. We are undertaking various analyses of this data. Because we can control what information the research participant receives, we can conduct quantitative analyses to assess and compare the accuracy of the legal claims. For example, who did the research participants bring the claim against? What legally relevant details are included or omitted in the claim? We are also conducting qualitative and quantitative analysis of the linguistic strategies used in the portal information and in the interviews.

\subsection{Phase III: Laboratory Testing of Technology-Assisted Online Evidence Acquisition}

Drawing on the results of Phase I and II, we will prototype empirically supported alternative online methods to try and correct for any deficits laypeople commonly have in explaining a dispute. Although these prototypes are dependent on the earlier results, we anticipate using approaches that enhance current mechanisms, such as:

- $\quad$ Explicit timelines: to help structure sequences of events

- Map-based interfaces: to help structure geographical information

- Joint evidence spaces: in contrast to isolated adversarial information silos

- Text filtering: to identify types of language that may be unhelpful to the presentation of a litigant's case

- Conversational interface: where a software agent interacts via a questionand-answer dialogue

Other possibilities to explore are providing content-based feedback and the effect of nudges. Content-based feedback is where the user receives some feedback about the content he or she has entered. Advanced content understanding by artificial intelligence is still largely in the future, but there is a substantial design space in-between the extremes of artificial intelligence that mimics content reading by a person and no feedback at all. Password strength metres are an example of a common content-based feedback mechanism in this space. ${ }^{31}$ Feedback could be given about simple matters, such as length, spelling, and grammar. It is also possible to provide feedback, by using sentiment analysis, about the use of emo-

30 Conversation with Dr. H. Macdonald (Toy-Cronin, July 2017); C. Coumarelos et al., Legal Australia-Wide Survey: Legal Need in Australia, Sydney, New South Wales Law and Justice Foundation, 2012; H. McDonald \& Z. Wei, How People Solve Legal Problems: Level of Disadvantage and Legal Capability, Sydney, Law and Justice Foundation of New South Wales, 2016.

31 B. Ur et al., 'How Does Your Password Measure Up? The Effect of Strength Meters on Password Creation', Proceedings of the 21st USENIX Security Symposium, 2012, pp. 65-80. 
tional language in users' entries/claims. This, of course, raises interesting questions about what type of feedback should be given and whether suggesting reducing emotional language will result in the litigant feeling they have not been 'heard'. ${ }^{32}$ Content feedback could also include the type of feedback that is typified by Amazon.com: social feedback from the behaviour of other users. Whereas an ecommerce platform might say, 'Shoppers who bought this item also bought these other items', a dispute resolution portal might say, 'Claimants who provided descriptions of a similar length were successful in $30 \%$ of their claims.'

The effect of nudges - prompts that are built into an interface - can also be usefully explored. Any interface will present choices to the users in different ways, for example a default option or the size of a text-entry box allows the designer to nudge the user into a desired response. ${ }^{33}$ In the online court context, an example of a nudge might be the provision of a default monetary option in a resolution process. Such a default will likely increase the selection of a monetary remedy relative to a 'neutral' interface that forces a user to explicitly choose a monetary remedy.

To explore these ideas, we will initially conduct usability testing with paperbased or nonfunctional interface prototypes. This will be followed by the development of a computational prototype demonstrating a new approach for litigants to provide details of their case. The computational prototype will be evaluated through user-testing, bringing a representative sample of the community into the laboratory to interact with the prototype. Multiple rounds of prototyping and user feedback will be conducted. We can then assess the extent to which the prototype addresses the issues identified in Phase I and II. The prototyping goes beyond testing for usability, however. The use of nudging and content-based feedback has to be designed with explicit aims in mind. Even simple form-based interface designs contain many implicit assumptions. We will tease out these explicit and implicit aims, placing them in the context of wider civil justice theory and policy.

\section{Conclusions}

What is required of an online court to assist litigants in providing accurate and relevant information in a manner that is accessible to the decision maker and opposing party? This question must be answered before an online court might provide genuine access to justice and not merely act as an initiative to reduce costs to the state but with the appearance of accessibility. We hope this research

32 This goes to questions of an online portal's effect on a litigant's sense of procedural justice. See T. R. Tyler, 'Procedural Justice', in D. A. Krauss \& J. D. Lieberman (Eds.), Jury Psychology: Social Aspects of Trial Processes, Surrey, Ashgate Publishing Limited, 2009.

33 M. Weinmann, C. Schneider, \& J. vom Brocke, 'Digital Nudging', Business \& Information Systems Engineering, Vol. 58, No. 6, 2016, pp. 433-436 (reframed nudging as digital 'choice architecture'); N. J. Belkin et al., 'Query Length in Interactive Information Retrieval', Proceedings of the 26th Annual ACM International Conference on Research and Development in Information Retrieval (SIGIR'03), 2003, pp. 205-212 (showed that changing the textual prompt associated with a search query produced longer queries [which usually produces better quality results]). 
will provide information that will complement the results of user-testing, as well as some practical ideas and suggestions, to help make the intention of accessibility a reality.

\section{Acknowledgements}

This project is co-funded by the University of Otago Legal Issues Centre and New Zealand Law Foundation. 